Revista Bioética

\title{
PESQUISA
}

\section{Inovação biomédica e ética: técnicas substitutivas na experimentação animal}

Tatiana Tavares da Silva ${ }^{1}$, Marilena Cordeiro Dias Villela Corrêa ${ }^{1}$

1. Universidade do Estado do Rio de Janeiro, Rio de Janeiro/RJ, Brasil.

\section{Resumo}

A utilização de animais não humanos como ferramenta de pesquisa biomédica e em testes da indústria para consumo humano foi incorporada às práticas científicas e assimilada como fundamental. A revisão sistemática dos resultados de protocolos de fases pré-clínicas não é prática corrente, mas metanálises recentes questionam a capacidade de projeção desses dados para a espécie humana. Atualmente, junto com o questionamento científico há abrangente discussão ética sobre os conflitos inerentes à instrumentalização da vida do animal não humano, cujo ápice é alcançado na criação de animais transgênicos. O objetivo deste artigo é discutir a aplicação do conceito de vulnerabilidade ao animal não humano no contexto da experimentação e pensar as relações de poder implícitas nessas práticas. Como aplicação prática da teoria exposta, propõe-se implantar e desenvolver técnicas substitutivas ao modelo animal, que conjuguem ética e inovação.

Palavras-chave: Modelos animais. Experimentação animal. Ética em pesquisa. Estudo sobre vulnerabilidade.

\section{Resumen}

\section{Innovación biomédica y ética: técnicas alternativas a la experimentación animal}

El uso de animales no humanos como herramienta para la investigación biomédica y en pruebas de la industria para el consumo humano se ha incorporado a las prácticas científicas y se ha asimilado como fundamental. La revisión sistemática de los resultados de protocolos de fases preclínicas no es una práctica corriente, pero metaanálisis recientes cuestionan la capacidad proyección de estos datos a la especie humana. Actualmente, junto con el cuestionamiento científico, hay una discusión ética sobre los conflictos inherentes a la instrumentalización de la vida del animal no humano, que alcanza su ápice en la creación de animales transgénicos. Este artículo tiene como objetivo discutir la aplicación del concepto de vulnerabilidad al animal no humano en el contexto de la experimentación y proponer una reflexión sobre las relaciones de poder implícitas en estas prácticas. Como una aplicación práctica de la teoría expuesta, se propone implantar y desarrollar técnicas alternativas al modelo animal, que conjuguen ética e innovación.

Palabras clave: Modelos animales. Experimentación animal. Ética en investigación. Estudio de vulnerabilidad.

\begin{abstract}
\section{Biomedical innovation and ethics: alternatives to animal testing}

The use of non-human animals has been incorporated into scientific practices as an essential biomedical research tool and in industry tests for human consumption. The systematic review of protocol results of preclinical phases is not a common practice, but recent meta-analyses question the projection accuracy of these data for humans. Currently, along with scientific questioning, there is a comprehensive ethical discussion about the conflicts in the instrumentalization of non-human life, which reached its peak with the creation of transgenic animals. This article discusses the application of the concept of vulnerability to non-human animals in experiments and reflects on the implicit power relations of these practices. We propose to implement and develop alternative techniques to the animal model, combining ethics and innovation.
\end{abstract}

Keywords: Models, animal. Animal experimentation. Ethics, research. Vulnerability study.

Declaram não haver conflito de interesse. 
Técnicas substitutivas ao uso de animais não humanos na pesquisa biomédica e industrial são a mais fidedigna expressão da ética aplicada à defesa, à proteção e ao reconhecimento do status moral do animal não humano em contexto de vulnerabilidade e opressão. Quando se compara a condução da ética em pesquisa com humanos à experimentação animal, observa-se imenso abismo entre os cuidados éticos adotados na primeira e os procedimentos descritos em documentos das fases pré-clínicas. Enquanto com humanos deve-se evitar ou minimizar qualquer dano aos participantes, nas fases pré-clínicas o desfecho leva à morte do animal ou Ihe causa danos irreparáveis ${ }^{1,2}$. O mesmo se aplica aos testes da indústria de produtos para consumo humano - sobretudo a indústria química -, que causam grande sofrimento aos animais.

Em países em desenvolvimento, como o Brasil, apesar das evidências do sofrimento e dos danos infligidos aos animais não humanos, estes ainda são utilizados em testes na indústria. Porém, em países que tradicionalmente discutem o tema e onde movimentos sociais de proteção animal estão mais consolidados (como na União Europeia), tais práticas não são mais aceitas ${ }^{1}$.

A aplicação do conceito de vulnerabilidade do animal não humano na experimentação é a base da discussão deste trabalho. A partir do reconhecimento do estado de vulnerado desses seres nesse contexto, o artigo apresenta abordagem teórica empenhada em mudar a forma como os animais não humanos são tratados na ciência contemporânea. O objetivo é promover a consolidação de políticas públicas que visem implementar técnicas substitutivas na pesquisa, no ensino e na indústria, sobretudo em países em desenvolvimento que ainda não integraram essa questão como necessária.

\section{Método}

Este estudo empreendeu extensa revisão bibliográfica não sistemática sobre o uso científico do modelo animal, analisando ainda documentos oficiais de órgãos regulamentadores da União Europeia, da Grã-Bretanha, do Brasil, dos Estados Unidos e do Canadá. Também se buscaram ativamente dados do Conselho Nacional de Controle de Experimentação Animal (Concea) - órgão do Ministério da Ciência, Tecnologia e Inovações (MCTI) brasileiro - referentes ao cadastro de centros de pesquisa que tiveram protocolos aprovados para testes com animais. A análise ética feita a partir dos dados levantados enfoca o estado de vulnerabilidade do animal não humano no contexto da experimentação, cuja participação se coloca a partir de perspectiva utilitarista.

\section{Modelo animal em testes de oncotoxicidade}

O animal não humano é considerado ferramenta básica da pesquisa biomédica - ideia perpetuada pelo discurso da própria ciência, que mantém essa prática ${ }^{1,2}$. No entanto, questões atuais de saúde pública, como estudos sobre a ação do vírus zika no cérebro fetal, ajudaram a questionar esse conceito. A ausência de conhecimento científico sobre qual seria o modelo animal ideal para entender a ação do zika sobre as células do cérebro humano levou pesquisadores a elaborar técnicas substitutivas, desenvolvendo microcérebros a partir de células-tronco humanas ou células neuronais, já que o emprego de camundongos não fornecia as respostas necessárias. Esse tipo de inovação técnica fez avançar as pesquisas ${ }^{3}$.

É comum questionar qual seria o animal adequado para determinado estudo no início de uma investigação. No entanto, não há respostas definitivas a essa pergunta e, em pesquisas pregressas, como a da pólio, o uso inadequado do modelo animal, assim como a interpretação errônea de dados obtidos com ele, retardaram a pesquisa para produzir a vacina humana ${ }^{4}$. Apesar de impregnado na cultura e na prática científica, historicamente o modelo animal nem sempre foi bem aceito pela comunidade acadêmica. $O$ conceito de que esse seria o padrão-ouro da pesquisa só se tornou corrente a partir dos anos 1950. Até então, pequenos animais, como cobaias, coelhos e ratos, eram comprados em mercados ou diretamente de criadores, e o meio científico desconfiava dos resultados obtidos devido à não padronização dos animais ${ }^{5}$.

A ciência não está alheia às políticas de mercado que impulsionam o mundo globalizado, e a inserção do modelo animal na pesquisa também foi movida por interesses industriais. A evolução técnico-cientifica do século XX estava intimamente associada ao desenvolvimento pós-Revolução Industrial e levou a grandes mudanças na forma de produção científica e de fármacos (de artesanal a industrial, em larga escala). A instituição do sistema de produção em massa de medicamentos intensificou o uso de animais em testes pré-clínicos e químicos para produtos de consumo humano ${ }^{6}$.

Desde o primeiro bioensaio relatado, em 1915 - quando Yamagiwa e Ichikawa demonstraram 
que o alcatrão de carvão causava câncer de pele na orelha de $\operatorname{coelhos}^{6,7}$-, os testes de toxicidade realizados rotineiramente pela indústria de consumo humano, e não apenas para fins medicamentosos, têm implicado a morte de milhões de animais sencientes, em sua maioria mamíferos ${ }^{8}$. Os bioensaios para potencial carcinogênico, além de exigirem o uso de número exorbitante de animais, caracterizam-se por produzir neles grau elevado de sofrimento, dor e estresse ${ }^{2,9,10}$. Pesticidas de longa duração, por exemplo, são testados em cães (beagles), resultando sempre em prolongado sofrimento seguido de morte. Esses testes utilizam duas espécies diferentes (roedores e não roedores) em estudos de ingestão dose-repetida subcrônicos (duração de 90 dias) e crônicos (12 meses) - ou seja, de longa duração ${ }^{11,12}$.

Fator importante na pesquisa biomédica, que faz determinado animal não humano ser definido como padrão em certo estudo ou teste, é a necessidade de replicar resultados. O uso repetido de determinada espécie pela comunidade científica, em nome da comparação de dados, perpetua o ciclo. Dependendo das técnicas empregadas e de seu grau de invasividade, submete-se reiteradamente a sofrimento enorme quantidade de animais ${ }^{1}$.

\section{Dificuldade de projeção de dados interespécies}

Apesar do uso crescente e desmesurado de animais não humanos em testes de toxicidade, os resultados são insuficientes para garantir a segurança, eficácia e a real capacidade de projeção dos dados para a espécie humana. Em termos práticos, a aplicação de testes de toxicidade tradicionais é inviável, pois exige número absurdamente elevado de animais para responder às exigências de órgãos regulamentadores, as quais levariam à realização de testes por amostragem, tornando bastante questionável a avaliação de segurança para uso da substância testada em humanos ${ }^{2}$. Tal exigência caminha em sentido oposto à redução do uso de animais, preconizada pelo conceito dos $3 \mathrm{R}$ (replacement, reduction, refinement) proposto por Russel e Burch ${ }^{13}$ em 1959.

A dificuldade de avaliar a toxicidade hepática é o maior problema da indústria farmacêutica e a grande responsável pela retirada de medicamentos do mercado já na fase de comercialização. Isso ocorre devido à diferença das propriedades histo e bioquímicas de metabolização da célula hepática de outras espécies em comparação com a humana ${ }^{14,15}$. A diferença interespécies de metabolização hepática e renal é a principal causa das altas taxas de falência de estudos pré-clínicos com animais não humanos para desenvolvimento de fármacos ${ }^{7,16}$ e pode explicar por que milhões de dólares gastos em pesquisa básica levam a poucos avanços clínicos.

Na análise de carcinogêse, as variáveis fisiológicas e suas expressões são muito diferentes mesmo entre espécies com DNA semelhante (caso dos grandes primatas e humanos), afetando os resultados de testes farmacêuticos e da indústria de consumo ${ }^{17}$. Outros fatores que contribuem para a disparidade de resultados são a grande variação metodológica dos protocolos, o tipo de pesquisa, as espécies utilizadas e variações interespécie e intersexo, que influenciam a análise de parâmetros de toxicocinética e farmacocinética, apesar de se tentar controlar ao máximo as variáveis dos protocolos de pesquisa pré-clínica.

Realizar estudos de metanálise na área de pesquisa básica é tarefa complexa, dada a dificuldade de homogeneizar protocolos na fase pré-clínica em comparação com as fases clínicas dos protocolos com humanos. A própria via de alimentação, se ad libitum ou gavagem (alimentação forçada com o intuito de controlar quantidade ingerida), já é suficiente para gerar resultados divergentes. Além disso, podem-se citar fatores fisiológicos alterados e diferenças na velocidade da metabolização celular dos animais (de roedores em relação a humanos, por exemplo). Ainda assim, estudos de metanálise evidenciaram erros metodológicos frequentes: uso de apenas uma cepa de animal (roedores) ou de um só sexo; uso de animais jovens, sem variação etária; tamanho inadequado dos grupos; estresse físico e psíquico; exposição (relacionada a tempo e quantidade) inadequada às drogas; entre outros ${ }^{2,17,18}$.

\section{Vulnerabilidade do animal não humano na experimentação}

O animal não humano está contido não apenas pela gaiola do biotério, mas pela estrutura poderosa de uma ciência dogmática que exerce forte influência na sociedade em que está inserida, produzindo-se e reproduzindo-se como formadora de opinião. Há também uma cadeia industrial que o aprisiona, detentora de lucros exorbitantes, e ainda uma estrutura política, que no caso específico da experimentação determina leis que permitem práticas questionáveis em nome da ciência ou do mercado ${ }^{1,2}$. Há, portanto, toda uma estrutura que naturaliza esses processos e nega o sofrimento e a vulnerabilidade de animais não humanos. 
Na experimentação, em particular, esses seres são descaracterizados de sua identidade como animais e tratados como objetos para satisfazer a curiosidade científica. É nesse âmbito que se encontram as situações mais críticas, com diversas questões éticas implícitas, já que as práticas incluem manter animais restringidos e em sofrimento físico e psíquico.

Chega-se ao máximo da instrumentalização no caso dos animais transgênicos, cuja vida é limitada a laboratórios de biossegurança. Seu processo de vida e morte é determinado pelos profissionais, e o único intuito de sua existência é servir para a busca incerta de um saber ${ }^{1,2,9}$ que, caso chegue a ser produzido, não os beneficiará. O conhecimento acerca da fisiologia desses animais é pequeno, e há indícios de que sua sensibilidade à dor seja maior ${ }^{19}$.

Adotar apenas alguns dos princípios contidos nos 3R, como a redução e o refinamento, não é solução definitiva para as questões éticas envolvidas na experimentação. A substituição é a única forma de se atingir desenvolvimento científico ético, e os dois princípios antes citados são apenas um mínimo a ser considerado no trato com animais ${ }^{13}$. Por mais que se aperfeiçoe o bem-estar animal, não será possível rescindir o sofrimento imposto a esses seres mantendo as práticas correntes. É preciso desenvolver técnicas substitutivas. Como quantificar o sofrimento? Nem mesmo entre indivíduos da mesma espécie são uniformes as respostas à dor física, ao medo em situação de perigo iminente ou de intenso desconforto, ao confinamento, ao contato frio e impessoal de quem o manipula, entre outros ${ }^{2}$.

O grau de desenvolvimento tecnológico atingido no século XXI permite criar animais geneticamente modificados para diversas finalidades, inserindo genes humanos ou bloqueando genes nativos, levando ao ápice da instrumentalização da vida. E por que o desenvolvimento de técnicas substitutivas não progrediu na mesma velocidade? Por que não se prioriza refletir sobre questões éticas do uso de animais e modificar rapidamente as práticas correntes?

Nesse processo, todos os atores envolvidos têm responsabilidade. O pesquisador, que elabora o projeto e define métodos, pode procurar usar ou não técnicas substitutivas. Seus assistentes, que participam diretamente da execução do protocolo, e todos aqueles que manipulam os animais em diferentes níveis também estão implicados. As editoras, por sua vez, deveriam analisar se os estudos a que se dispõem disseminar foram conduzidos de maneira ética estabelecendo políticas de publicação que estimulem boas práticas de experimentação. Trata-se de esforço que também deveria ser empreendido pela indústria, que, ao invés de buscar manter métodos tradicionais de testes a fim de assegurar as mesmas margens de lucro, poderia investir na pesquisa de técnicas substitutivas.

Há ainda os fundos de apoio à pesquisa científica que privilegiam técnicas tradicionais e não estimulam outros modelos de pesquisa; os órgãos de fiscalização, que não punem instituições que utilizam animais de modo inadequado; e os comitês de ética, que não determinam técnicas substitutivas. Por fim, destacam-se as universidades, polos geradores de opinião e de futuras gerações de pesquisadores e professores, que não colocam o tema em pauta e mantêm o que vem sendo feito há séculos: forma engessada de ensino baseada apenas na tradição, sem reflexão ou inovação, naturalizando a produção de conhecimentos quando se trata de animais não humanos, em postura diferente da assumida nos ensaios clínicos com humanos.

Ótica utilitarista norteia as decisões pertinentes à experimentação animal, visando apenas os interesses humanos. Os animais não estão no centro das decisões referentes às diversas fases do processo - são apenas objetos submissos dentro de uma esfera de poder e propriedade, desde a elaboração do protocolo, passando pelas análises dos comitês de ética até as regulamentações que norteiam os procedimentos e o destino final dos animais envolvidos.

Até hoje, a produção científica é regida por conceitos éticos clássicos, segundo os quais só o ser humano é portador de consideração moral ${ }^{2}$. Para Verdú Delgado e García García ${ }^{20}$, é necessário fortalecer nas ciências sociais postura crítica em relação ao tratamento fornecido aos animais não humanos, desenvolvendo atitude reflexiva sobre o exercício disfuncional do poder. Para tanto, os autores propõem introduzir os interesses dos animais não humanos nos debates bioético e socioético, a despeito dos interesses humanos, mediante três perspectivas metodológicas: distributiva de investigação, estrutural e dialética (ou sociocrítica). Por meio delas, a realidade observada fornecerá dados objetivos (qualidades absolutas), interpretáveis (qualidades relativas) e em transformação (qualidades reflexivas).

$\mathrm{Na}$ categoria absoluta figura o antropocentrismo, pois a desigualdade de poder nas relações entre diferentes seres biológicos legitima o discurso de superioridade humana e o monopólio dos recursos do planeta pelo homem. Quanto à relativa, 
aceita-se que existam outros pontos de vista e que se deve analisar a exploração dos animais. Finalmente, na análise reflexiva propõe-se que as necessidades dos animais não humanos também sejam consideradas importantes.

A legitimação do exercício de poder depende da cultura de cada sociedade. Se determinado ato é considerado legítimo e até mesmo benéfico no meio social, não se costuma caracterizá-lo como mau ou antiético; pelo contrário, por vezes ele é aceito inclusive legalmente. Em suma, tal análise mostra em que medida a verdade e a justiça são construídas por sistemas culturais que reafirmam o poder imposto pelo mais forte. Ocasionalmente, disso resulta tornar invisível o animal não humano em processos de que este é vítima, como experimentação ou abate, como se tudo tivesse sido obtido sem contato com ele. Dissocia-se a exploração da ideia de um sujeito vivo, de modo a mantê-lo como objeto, diminuindo o impacto do ato perpetrado, minimizando ou fazendo desaparecer a agressão ${ }^{20}$.

A partir do século XIX, a violência perpetrada contra o animal não humano se tornou cada vez mais organizada e estruturada, tendência que se intensificou com o desenvolvimento dos mercados que mobilizaram a economia no século XX. $O$ interesse econômico é um dos fatores que levam à exclusão desses seres de nosso sistema moral. Nesse contexto de exploração e propriedade, explicam os abusos a objetificação do animal e a ausência de limites da conduta humana em relação a outras espécies.

Embora a filosofia moral continental, também denominada "filosofia europeia moderna", mantenha visão antropocêntrica, a questão do animal é mais amplamente discutida e organizada a partir do século $X X$, por influência dos movimentos sociais e da perspectiva liberal e humanista ${ }^{21}$. A corrente utilitarista preferencial de Singer ${ }^{22}$ argumenta em favor da inclusão dos animais não humanos em nossa esfera moral, valorando sua vida ${ }^{22}$. No entanto, ainda há obstáculos para colocar essa perspectiva em prática.

Há certo limite a partir do qual a barreira entre o interesse humano e o do animal torna-se intransponível. Isso é bem exemplificado ao se analisar dados de órgãos oficiais da União Europeia, da Grã-Bretanha e do Canadá, que revelam número ainda bastante expressivo de animais utilizados e expostos a graus intensos de dor e outros tipos de sofrimento, além de uso de anestésicos muito abaixo do que deveria ser admitido. Considera-se aceitável até mesmo realizar procedimentos dolorosos sem anestesia. Onde se enquadra, nesse cenário, a maximização do prazer, o não infringir dor e sofrimento a outrem em troca de duvidoso resultado em determinado projeto de pesquisa? Se realmente o interesse do animal não humano estivesse dentro de nossa esfera moral, tais atos não seriam permitidos.

Mesmo que o modelo animal servisse perfeitamente para projetar resultados científicos, tais sofrimentos e agressões não se justificam eticamente. O animal não humano, completamente vulnerável dentro dessa estrutura, deveria ser protegido ${ }^{23,24}$. $\mathrm{O}$ argumento utilitarista comumente utilizado para justificar a experimentação - o sofrimento de alguns animais não humanos para benefício de milhões de humanos - não se sustenta, pois na realidade o dilema é o sofrimento de milhões de animais não humanos visando benefício hipotético, impossível de ser quantificado, a seres humanos ${ }^{1}$.

Também é necessário ressaltar que medicamentos ou tecnologias produzidos pela indústria farmacêutica ou de instrumentos médicos não são acessíveis para grande parte da população mundial, pois têm alto custo. Portanto, o discurso de que o uso de animais visa ao benefício humano não é claro quanto a seu real objetivo: o lucro.

$\mathrm{Na}$ análise utilitarista clássica, em que se considera a maximização do prazer e a minimização da dor em relação ao futuro benefício gerado para outros, o animal não humano, submetido a dor e sofrimento, deveria ser protegido, e portanto as práticas atuais não se justificariam. Já na análise utilitarista preferencial, não estariam a maximização do prazer ou a minimização da dor em questão, mas os interesses dos afetados pelo ato ${ }^{22,25}$. E é evidente o interesse de qualquer ser, inclusive o animal não humano, em não sofrer.

Quando se fala em "dor", não se trata apenas de dor física momentânea, passível de ser suprimida por anestésico de ação fugaz, mas também do sofrimento imposto em todas as etapas do processo: o medo, a dor após o procedimento e a percepção do que é feito com outros animais ao redor, inclusive filhotes ${ }^{19}$. A antiga ideia de que animais não perceberiam o que acontece com eles ou o que Ihes poderia acontecer no futuro, e por isso sofreriam menos que o humano, podendo portanto ser utilizados em experimentos, tem cada vez menos respaldo, seja científico (capacidades neurocognitivas já foram detectadas em animais sencientes) ou ético ${ }^{2,24}$.

No entanto, há todo um discurso que visa manter as práticas vigentes, veiculado em meios de comunicação, salas de aula, congressos e publicações científicas de revistas especializadas ou 
dirigidas ao público leigo. A experimentação animal e seus resultados são sempre apresentados como grandes avanços, mesmo que haja apenas indícios de descobertas que em sua maioria não terão resultados práticos. Descreve-se o procedimento, mas não se ressalta o que foi feito com o animal não humano, ou seja, a metodologia adotada. Não se divulga que o animal usado no experimento era sadio e que foi lesado intencionalmente para os propósitos da pesquisa ${ }^{1}$, tornando invisíveis tanto a agressão como sua vítima ${ }^{20}$.

Aplicar os princípios dos 3R pela ótica do bem-estar, preconizando a diminuição do sofrimento sem enfocar a substituição, serve como proteção moral para o pesquisador. Tal aplicação permite que os procedimentos sejam realizados dentro da moralidade vigente, sem estabelecer novas normas morais e científicas - como seria eticamente desejável e esperado -, mas sem contribuir com resultados práticos para melhorar a realidade dos animais ${ }^{19}$. Já em perspectiva que associe a visão do bem-estar com o abolicionismo, o intuito inicial e imediato é a restrição, objetivando ações para extinguir o uso de animais em futuro próximo ${ }^{26,27}$. Enquanto isso não ocorre, milhões de seres necessitam de medidas para reduzir e refinar seu uso, visando diminuir o sofrimento gerado pelas práticas empregadas.

Os animais de laboratório não são escolhidos por acaso, nem por serem o melhor modelo para estudar determinada doença humana (até porque tal informação não existe previamente). Com base em trabalhos já publicados, repete-se exaustivamente determinado modelo a fim de comparar resultados. E a seleção considera determinadas características, como tamanho (preferencialmente pequeno) e fácil manipulação, contenção e manutenção em cativeiro, de modo a permitir que filhotes também sejam usados. Os animais que preenchem tais características são, por seleção "cientificamente" orientada, os mais vulneráveis. Os mais frágeis são deliberadamente escolhidos ${ }^{1}$.

O conceito de vulnerabilidade é muito abordado na área da bioética e da ética em pesquisa quando aplicado a grupos humanos, mas sua extensão para animais não humanos ainda é pouco discutida. Todos os seres vivos são vulneráveis ${ }^{28,29}$, sujeitos a ofensa ou agressão. No entanto, há aqueles em situação de vulnerabilidade manifesta, que saíram de um estado latente, de ser, para um estado real, de estar, sem qualquer capacidade de se defender ${ }^{23,29}$. O fato de os animais não humanos não compreenderem moralmente e de forma totalmente racional o que acontecerá com eles, bem como a real magnitude da agressão que estão vivenciando, torna-os ainda mais vulnerados.

A vulnerabilidade pode ser definida como passiva ou ativa, e a definição terá implicações morais, sobretudo em sociedade antropocêntrica, na qual tradicionalmente se define o humano como ser ativo e o animal não humano como passivo ${ }^{30}$. Se a vulnerabilidade animal é considerada passiva, pode-se corroborar a ideia de suposta incapacidade, o que diminuiria seu valor em relação aos humanos. Tal vulnerabilidade decorreria do fato de o animal não humano ser um paciente moral, submetido às vontades do agente moral - a pessoa humana - capaz de julgar as próprias ações. Mas o animal tem capacidades intrínsecas a si e à sua espécie, de modo que a senciência e a vulnerabilidade podem ser consideradas características ativas.

Derrida $^{31}$, contribuindo para a ética animal, ressaltou uma interpretação da escrita de Bentham sobre a capacidade de sofrer dos animais: Bentham teria usado o verbo can, que na língua inglesa enfatiza essa capacidade como ativa, como realmente "ser capaz de" ${ }^{30}$. Nessa leitura, para Bentham ${ }^{32}$ nem a racionalidade nem a faculdade da fala eram importantes, mas sim a capacidade ativa de sofrer.

Segundo Calarco ${ }^{21}$, Derrida também associa essa capacidade com a incapacidade de evitar a dor, ressaltando a vulnerabilidade e a expondo, de modo a clamar por resposta moral ${ }^{30,31}$. Pois, de acordo com Derrida ${ }^{31}$, nos tornamos sujeitos morais quando reconhecemos a vulnerabilidade do outro. É a vulnerabilidade passiva que torna a ética necessária. Assim, do mesmo modo como Levinas ${ }^{33}$ mencionava a face do outro, Derrida ${ }^{31}$ falava no olhar do outro, mas considerando também o olhar do animal não humano (o que não ocorria em Levinas). Este encontro entre homem e animal, pelo olhar, levaria o humano a rever a si mesmo e romper com sua existência egoísta ${ }^{21,30-32}$.

Aqueles que permanecem com visão antropocêntrica não se conscientizam com o sofrimento do animal não humano, não percebem a necessidade de resposta moral. Vendo a incapacidade de lutar contra a agressão como fraqueza, o homem antropocêntrico falha em reconhecer a vulnerabilidade do animal não humano, considerando-o inferior ${ }^{30}$. No entanto, seres humanos também são passivos em sua vulnerabilidade. Nessa perspectiva, a ruptura que o animal provoca no humano não se deve às diferenças entre eles, mas às similaridades, como a finitude e o sofrimento.

Esquecendo momentaneamente o antropocentrismo, percebe-se que o animal não humano 
e o homem compartilham a vulnerabilidade, e que esta se sustenta não em passividade, mas em atividade bloqueada, impossibilitada de se manifestar. Ambos são ativos, mas ficam impedidos de se defender quando vulnerados. Portanto, o sofrimento não é passividade, mas ação frustrada. A senciência, nesse contexto, está entre a atividade e a passividade: ela capacita o animal a conduzir suas ações, mas também significa que o animal é vulnerável à ação de outros ${ }^{30}$.

Para Acampora ${ }^{34,35}$, a vulnerabilidade do corpo, comum ao homem e a animais não humanos, é a base para estender a compaixão moral a outros seres. Assim, o autor abre as portas a uma consideração moral que não apela à semelhança de capacidades para descrever sentimentos baseados no compartilhamento da vulnerabilidade. Ele parece sugerir, segundo Thierman ${ }^{24}$, que se pode prescindir de uma metafísica da moral que defina obrigações e responsabilidades com respeito ao outro animal. Bastaria colocar o corpo no primeiro plano do pensamento ético para reconhecer nossa vulnerabilidade, como animais que somos.

É evidente a associação entre o referencial bioético de vulnerabilidade e as legislações que protegem os humanos em pesquisas biomédicas. Apesar de o termo "vulnerabilidade" não aparecer de forma explícita nos documentos regulatórios, reconhece-se que há grupos mais suscetiveis ao dano ${ }^{1}$. É preciso estender esse reconhecimento aos animais não humanos.

\section{O que fazer? Uma proposta ética}

Com mais de 30 mil substâncias no mercado europeu a serem testadas, o que demandaria milhões de animais vertebrados, a European Consensus Platform on 3R Alternatives estimou a possibilidade de utilizar técnicas alternativas ${ }^{36}$. Respondendo à mesma preocupação, o projeto CarcinoGenomics foi elaborado para otimizar métodos in vitro para detectar o potencial carcinogênico de substâncias, substituindo bioensaios com ratos e camundongos ${ }^{37}$.

Ações da União Europeia, como a abolição em todo seu território de testes com animais na indústria cosmética, em 2009 , seguida da proibição de entrada e uso de matérias-primas testadas em países que permitem esse tipo de experimentação, em 2013, ajudaram a reduzir o uso de animais na indústria e a promover a pesquisa e o desenvolvimento de técnicas substitutivas ${ }^{38}$. No Brasil, passos iniciais foram dados nesse caminho com a Portaria 491/2012 do $\mathrm{MCTI}^{39}$, que criou a Rede Nacional de Métodos Alternativos, e a Resolução Normativa Concea $18 / 2014^{40}$, que reconheceu 17 técnicas substitutivas e estabeleceu prazo de cinco anos para que elas fossem colocadas em prática. Cabe citar, ainda, a criação do Centro Brasileiro para Validação de Técnicas Alternativas, da Fundação Oswaldo Cruz, em $2013^{41}$.

Mais recentemente houve um movimento positivo na América Latina com a criação da Plataforma Regional de Métodos Alternativos ao Uso de Animais do Mercosul, um programa de formação na área de técnicas substitutivas ao uso de animais e intercâmbio de tecnologias entre países-membros do Mercado Comum do Sul (Mercosul) e a União Europeia, que detém mais experiência nesse quesito. O movimento dentro do bloco comercial foi incentivado e impulsionado pelas necessidades de mercado advindas das relações comerciais com países europeus, como descrito na página do MCTI:

Ante a iniciativa da União Europeia de banir os produtos cosméticos testados em animais, para ser competitivo num mercado cada vez mais globalizado, faz-se necessário adequar a produção à luz de inovações tecnológicas que propiciem novos testes toxicológicos capazes de gerar resultados tão ou mais confiáveis que aqueles gerados por meio da experimentação com animais. (...) O Brasil deseja intercambiar sua experiência na área de métodos alternativos ao uso de animais com os demais países do Mercosul e com parceiros europeus. Isso porque em um futuro bem próximo é provável a existência de um cenário em que haverá drástica diminuição no uso de animais de experimentação para testes de produtos diversos. Esse cenário contribuirá grandemente com a economia baseada no conhecimento $e$ centrada na biotecnologia ${ }^{42}$.

Para tanto, torna-se necessário adotar medidas como fiscalizar o cadastro de protocolos de pesquisa no sistema do Concea e construir bancos de dados consistentes sobre técnicas substitutivas existentes, para servir a pesquisadores e estudantes já que um sistema de dados transparente sobre o uso de animais em pesquisas e testes no Brasil ainda não está disponível.

É importante também ressaltar o papel das comissões de ética para exigir que técnicas substitutivas já existentes sejam utilizadas e aceitar técnicas já validadas internacionalmente, a fim de evitar a repetição de todo o processo, o que levaria ao uso de mais animais sem justificativa. 
Os órgãos de fomento à pesquisa e as universidades também são fundamentais nesse esforço, e devem incentivar jovens pesquisadores a pensar projetos que busquem validar técnicas substitutivas. Da mesma forma, como dito, cabe às editoras assumir a responsabilidade por suas políticas de submissão, detectando trabalhos antiéticos e criando mecanismos para obrigar a publicação de dados negativos com resultados de experimentação animal.

\section{Considerações finais}

A vulnerabilidade do animal não humano, tão explícita no contexto da experimentação, exige resposta moral. São necessárias políticas públicas que estimulem o desenvolvimento e a adoção de técnicas substitutivas ao uso de animais em testes industriais, ensino e pesquisa, e que promovam o intercâmbio de inovações. O nível de desenvolvimento biotecnológico alcançado no século XXI demonstra a capacidade de gerar tecnologias moralmente adequadas, beneficiando tanto humanos como animais.

Há a necessidade moral de se retirar o animal não humano da esfera de sofrimento e morte em que se encontra para benefício exclusivo dos humanos. As argumentações a favor da manutenção do atual modelo, por supostamente ser esse o padrão-ouro, assim como as argumentações utilitaristas sobre o benefício e a segurança para a população humana, são discutíveis. Assim, havendo alternativa moralmente preferível, esta deve ser priorizada.

\section{Referências}

1. Silva TT, Corrêa MCDV. Ética na experimentação animal: limites e controvérsias de uma prática. Saarbrücken: Novas Edições Acadêmicas; 2016.

2. Rollin BE. Animal rights and human morality. $3^{3}$ ed. New York: Prometheus Books; 2006.

3. Garcez PP, Loiola EC, Costa RM, Higa LM, Trindade P, Delvecchio R et al. Zika virus impairs growth in human neurospheres and brain organoids. Science [Internet]. 2016 [acesso 12 nov 2019];352(6287):816-81. DOI: 10.1126/science.aaf6116

4. Guerrini A. Experimenting with humans and animals: from Galen to animal rights. Baltimore: Johns Hopkins University Press; 2003.

5. Kirk RGW. Wanted-standard guinea pigs': standardization and the experimental animal market in Britain ca. 1919-1947. Stud Hist Philos Biol Biomed Sci [Internet]. 2008 [acesso 12 nov 2019];39(3):280-91. DOI: 10.1016/j.shpsc.2008.06.002

6. Huff J. Chemicals studied and evaluated in long-term carcinogenesis bioassays by both the Ramazzini Foundation and the National Toxicology Program. Ann N Y Acad Sci [Internet]. 1999 [acesso 12 nov 2019];982(1):208-30. DOI: 10.1111/j.1749-6632.2002.tb04935.x

7. Knight A. The costs and benefits of animal experiments. London: Palgrave Macmillan; 2011.

8. European Parliament and the Council of the European Union. Directive 2010/63/EU of the European Parliament and of the Council of 22 September 2010 on the protection of animals used for scientific purposes. Official Journal of the European Union [Internet]. 2010 [acesso 12 nov 2019]. Disponível: https://bit.ly/2SztMNW

9. About the CCAC. Canadian Council on Animal Care [Internet]. 2008 [acesso 12 nov 2019]. Disponível: https://bit.ly/2SxbAEv

10. Knight A. Laboratory animal use in Great Britain in 2009. Altex [Internet]. 2010 [acesso 12 nov 2019];15(2):59-60. DOI: 10.11232/aatex.15.59

11. Box RJ, Spielmann H. Use of the dog as non-rodent test species in the safety testing schedule associated with the registration of crop and plant protection products (pesticides): present status. Arch Toxicol [Internet]. 2005 [acesso 12 nov 2019];79:615-26. DOI: 10.1007/s00204-005-0678-0

12. Box RJ. Replacement of dogs as research animals for the approval testing of plant protection products. Altex [Internet]. 2006 [acesso 12 nov 2019];23(1):24-7. Disponível: https://bit.ly/3nkolv3

13. Russel WMS, Burch LC. The principles of humane experimental technique [Internet]. Baltimore: Johns Hopkins Bloomberg School of Public Health; 1992 [acesso 12 nov 2019]. Disponível: https://bit.ly/2GSNWzB

14. Guengerich FP. Cytochrome P450s and other enzymes in drug metabolism and toxicity. AAPS $J$ [Internet]. 2006 [acesso 12 nov 2019];8(1):E101-11. DOI: 10.1208/aapsj080112

15. Bolker J. There's more to life than rats and flies. Nature [Internet]. 2012 [acesso 12 nov 2019];491:31-3. DOI: 10.1038/491031a

16. DiMasi JA, Hansen RW, Grabowski HG. The price of innovation: new estimates of drug development costs. J Health Econ [Internet]. 2003 [acesso 12 nov 2019];22(2):151-85. DOI: 10.1016/S0167-6296(02)00126-1

17. Hartung T. Comparative analysis of the revised Directive 2010/63/EU for the protection of laboratory animals with its predecessor 86/609/EEC: a t4 report. Altex [Internet]. 2010 [acesso 12 nov 2019];27(4):285-303. DOI: 10.14573/altex.2010.4.285

18. Matthews RAJ. Medical progress depends on animal models: doesn't it? J R Soc Med [Internet]. 2008 [acesso 12 nov 2019];101:95-8. DOI: 10.1258/jrsm.2007.070164 
19. Nuffield Council on Bioethics. The ethics of research involving animals. London: Nuffield Council on Bioethics; 2005.

20. Verdú Delgado A, García García JT. La gestión del poder en torno a la cuestión de los animales: aportaciones desde las ciencias sociales. Rev Bioét Derecho [Internet]. 2011 [acesso 12 nov 2019];23:64-72. Disponível: https://bit.ly/3ivKDvy

21. Calarco M. Zoographies: the question of the animal from Heidegger to Derrida. New York: Columbia University Press; 2008.

22. Singer P. Ética prática. São Paulo: Martins Fontes; 2002.

23. Felipe ST. Racionalidade e vulnerabilidade: elementos para a redefinição da sujeição moral. Veritas [Internet]. 2007 [acesso 12 nov 2019];52(1):184-95. DOI: 10.15448/1984-6746.2007.1.1868

24. Thierman S. The vulnerability of other animals. JCAS [Internet]. 2011 [acesso 12 nov 2019];9(1-2):182-208. Disponivel: https://bit.ly/36CiKzs

25. Paixão RL, Schramm FR. Experimentação animal: razões e emoções para uma ética. Niterói: Eduff; 2008.

26. Francione G. Animals as persons: essays on the abolition of animal exploitation. New York: Columbia University Press; 2008.

27. Salt H. Restrictionists and abolicionists. Rev Bras Direito Anim [Internet]. 2010 [acesso 12 nov 2019];5(6):33-6. Disponível: https://bit.ly/34tUxc5

28. Kottow M. Vulnerability: what kind of principle is it? Med Health Care Philos [Internet]. 2004 [acesso 12 nov 2019];7:281-7. DOI: 10.1007/s11019-004-6857-6

29. Hossne WS. Dos referenciais da bioética: a vulnerabilidade. Bioethikos [Internet]. 2009 [acesso 12 nov 2019];3(1):41-51. Disponível: https://bit.ly/3khZAmw

30. Aaltola E. Animal suffering: philosophy and culture. London: Palgrave Macmillan; 2012.

31. Derrida J. The animal that therefore I am. New York: Fordham University Press; 2008.

32. Bentham J. An introduction to the principles of moral and legislation. New York: Prometheus Books; 1982.

33. Levinas E. Totality and infinity. Dordrecht: Springer; 1991.

34. Acampora R. The problematic situation of post-humanism and the task of recreating a symphysical ethos. Between Species [Internet]. 1995 [acesso 12 nov 2019];11(1-2):25-32. Disponível: https://bit.ly/34y2hK2

35. Acampora R. Corporal compassion. Pittsburgh: University of Pittsburgh Press; 2006.

36. Rogiers V. Recent developments in the way forward for alternative methods: formation of national consensus platforms in Europe. Toxicol Appl Pharmacol [Internet]. 2005 [acesso 18 nov 2020];207(supl 2):S408-13. DOI: 10.1016/j.taap.2005.01.059

37. European Comission. European Union reference laboratory for alternatives to animal testing (EURL ECVAM) [Internet]. 2020 [acesso 18 nov 2020]. Disponível: https://bit.ly/3nAwVdB

38. European Union. Regulation (EC) no 1.223/2009 of the European Parliament and of the Council, of 30 November 2009. On cosmetic products. Official Journal of the European Union [Internet]. Brussels, 22 dez 2009 [acesso 3 nov 2020]. Disponível em: https://bit.ly/2Hh1plA

39. Brasil. Ministério da Ciência, Tecnologia e Inovação. Portaria no 491, de 3 de julho de 2012. Institui a Rede Nacional de Métodos Alternativos (Renama) e sua estrutura no âmbito do Ministério da Ciência, Tecnologia e Inovação (MCTI), que será supervisionada por um Conselho Diretor. Diário Oficial da União, Brasília, no 129, p. 19, 5 jul 2012. Seção 1.

40. Conselho Nacional de Controle de Experimentação Animal. Resolução Normativa Concea $\mathrm{n} 018$ de 24 de setembro de 2014. Reconhece métodos alternativos ao uso de animais em atividades de pesquisa no Brasil, nos termos da Resolução Normativa no 17, de 3 de julho de 2014, e dá outras providências. Diário Oficial da União [Internet]. Brasília, 25 set 2008 [acesso 16 jan 2020]. Disponível: https://bit.ly/2GF9j7l

41. Sobre o BracVAM. Centro Brasileiro para Validação de Técnicas Alternativas [Internet]. [s.d.] [acesso 6 out 2020]. Disponível: https://bit.ly/3d106Rq

42. Premasul. Ministério da Ciência, Tecnologia e Inovações [Internet]. c2020 [acesso 22 out 2020]. Disponível https://bit.ly/3jfw67C

\section{Participação das autoras}

Tatiana Tavares da Silva concebeu o artigo e, com Marilena Cordeiro Dias Villela Corrêa, redigiu o texto e trabalhou na revisão final.

\section{Correspondência}

Tatiana Tavares da Silva - Rua Gustavo Sampaio, 244, apt. 404A, Leme CEP 22010-010. Rio de Janeiro/RJ, Brasil.

Tatiana Tavares da Silva - Doutora - tavares_tatiana@yahoo.com.br

(iD) 0000-0001-5738-0321

Marilena Cordeiro Dias Villela Corrêa - Doutora - correamarilena@gmail.com

(iD) 0000-0003-1742-8639

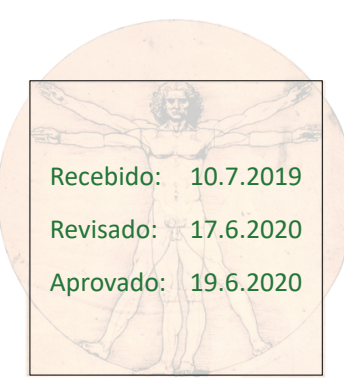

